\title{
Simulation of Infiltration of Molten Alloy to Porous Preform Using Low Pressure*
}

\author{
Yong Bum $\mathrm{CHOI}^{* *}$, Gen SASAKI ${ }^{* *}$, Kazuhiro MATSUGI ${ }^{* * *}$, Naoki SORIDA****, \\ Shunsaku $\mathrm{KONDOH}^{* * * *}$, Toshio FUJII** and Osamu YANAGISAWA***
}

\begin{abstract}
Metal-fiber-preform-reinforced aluminum alloy composites were prepared by the infiltration of molten metal using a low-pressure casting process. The infiltration behavior of the filling pattern and the velocity profile obtained for alloys fabricated by the low-pressure casting process was investigated. A thermocouple was inserted into the preform to observe the infiltration behavior. The infiltrations at pressure acceleration times of $1 \mathrm{sec}, 2 \mathrm{sec}$ and $5 \mathrm{sec}$ under a constant pressure of $0.4 \mathrm{MPa}$ were respectively complete in $0.4 \mathrm{sec}, 0.8 \mathrm{sec}$ and $1.2 \mathrm{sec}$. Under these conditions, molten aluminum alloy successfully infiltrated on $\mathrm{FeCrSi}$ metal fiber preform by the low-pressure casting process. The porosity of composites was observed to determine their reliability. An automobile piston was developed with an $\mathrm{FeCrSi}-$ reinforced aluminum alloy that has $0 \%$ porosity using the optimal applied pressure and pressure acceleration times.
\end{abstract}

Key Words: Low-Pressure Casting, Infiltration Behavior, Molten Aluminum Alloy, Preform

\section{Introduction}

To utilize aluminum alloy matrix composites (AlMMCs) for automobile parts, improvements in the mechanical properties and reliability of the composites are required. The squeeze casting process is advantageous for obtaining high-performance composites and actually, many automobile engine parts such as engine pistons, cylinder liners, engine block discs and so on have been developed $^{(1),(2)}$. However, these composites are expensive and are not suitable for the preparation of automobile parts with complex shapes.

Producing an aluminum alloy casting with a lowpressure casting process has the advantage of being semiautomatic and thus reducing labor costs as well as a obtaining a better casting quality and a higher yield ${ }^{(3),(4)}$. It is believed that the costs of low-pressure casting is lower than that of squeeze casting and that the process provides a better quality than gravity casting. In spite of its many

* Received 17th June, 2005 (No. 05-4198)

** Hiroshima Prefectural Institute of Industrial Science and Technology, Higasi-Hiroshima 739-0046, Japan.

E-mail: ybchoi@ hiroshima-u.ac.jp

*** Department of Mechanical Engineering System, Hiroshima University, Higasi-Hiroshima 739-8527, Japan

**** Testing \& Research Gr. Development Dept. Kolbenschmidt K.K., Higasi-Hiroshima 739-2124, Japan advantages, the low-pressure casting process has not yet been fully appreciated and as used as widely as it should. The main problem is the lack of understanding of the process, that is to say, the die design and operation have not been properly incorporated into machines to make the best of the process ${ }^{(5)}$.

Recently, the infiltration technique with a low pressure has been used for the preparation of AlMMCs for automobile parts because of its high cost effectiveness and easy handling. Oda et al. developed an $\mathrm{Al} / \mathrm{MMC}$ diesel engine piston by the low-pressure casting process ${ }^{(6)}$.

In this study, we investigate the infiltration behavior of filling pattern and the velocity profile obtained for alloys fabricated by the low-pressure casting process. A thermocouple was inserted in the preform to observe the infiltration behavior. The aim of this study is to develop an approach to developing and applying an engine piston head part made of $\mathrm{FeCrSi} / \mathrm{A} 336.0$ alloy composites.

\section{Materials and Experimental Procedure}

A schematic diagram of a typical low-pressure casting process is shown in Fig. 1 (a). A low-pressure casting machine usually includes a pressurized mould, a compressor, a vacuum pump and an air vent that removes the air in the preform before applying pressure. For removing the air in the preform, pressure was reduced by approximately $-0.09 \mathrm{MPa}$ at the air vent for $5 \mathrm{sec}$ after pouring 




(a)

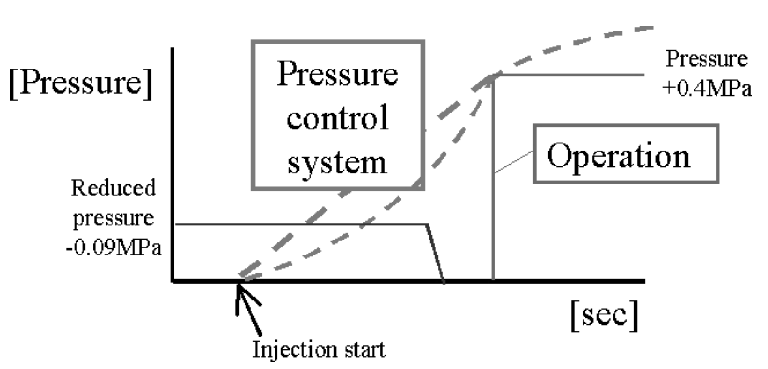

(b)

Fig. 1 Schematic diagram of typical low-pressure casting

molten aluminum alloy. Then a pressure of $0.4 \mathrm{MPa}$ was applied from the top. The process of low-pressure casting is shown in Fig. 1(b). A336.0 (Al-11-13\%Si-0.8$1.5 \% \mathrm{Ni}-0.8-1.3 \% \mathrm{Cu}-0.7-1.3 \% \mathrm{Mg}$ ) aluminum alloy was used as a molten metal to infiltrate the preform. The preheating temperature of the preform was $400^{\circ} \mathrm{C}$. The preform was set in the metal mould. The temperature of the mould was approximately $200^{\circ} \mathrm{C}$. Molten aluminum with a temperature of $750^{\circ} \mathrm{C}$ was poured into the mould. Filling velocity measurements were carried out using a thermocouple with a $1 \mathrm{~mm}$ diameter that was put in the preform with 8 holes. The position of thermocouple in the preform and the preform size are shown in Fig. 2. Therefore, the filling velocities at pressure acceleration times of $1 \mathrm{sec}$, $2 \mathrm{sec}$ and $5 \mathrm{sec}$ are investigated under a constant pressure of $0.4 \mathrm{MPa}$. The thermocouple was used to measure the variation in temperature, which indicates the filling velocities when molten alloy was infiltrated in the preform. The molten alloy was infiltrated from the side and bottom of the preform. The upper part of the preform was not infil-

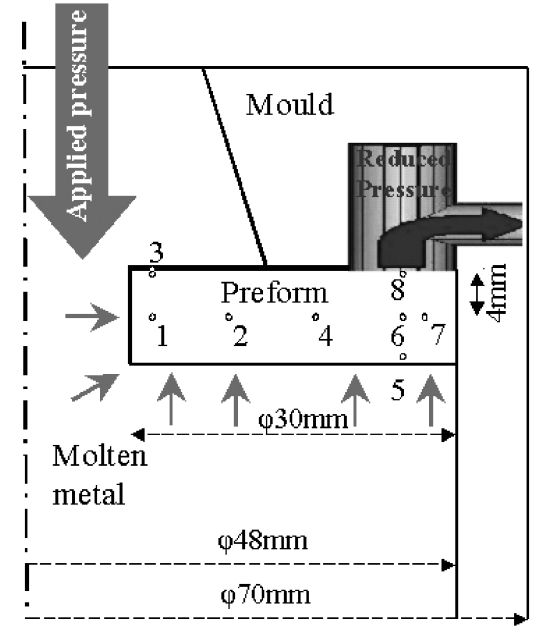

Fig. 2 Thermocouple position and preform size

trated. There is a plate on the preform. In our previous study ${ }^{(7)}$, the molten aluminum flows from different directions impinge on each other in preform and thus turbulent flows are generated.

\section{Results and Discussion}

\subsection{Infiltration behavior}

The filling velocities at pressure acceleration times of $1 \mathrm{sec}, 2 \mathrm{sec}$ and $5 \mathrm{sec}$ are investigated under a constant pressure of 0.4 MPa. The thermocouple measured the variation in temperature rapidly when the pressure of $0.4 \mathrm{MPa}$ was applied to the molten alloy. Then the molten alloy infiltrates the preform. However, from this Figs. 3-5, it can be seen that there is an effect at the reducing pressure before applied pressure. Thermocouples Nos. 1 and 2 were used to observe the variation in temperature rapidly by the reducing pressure. The infiltration of molten alloy was expected inside preform. In the case of thermocouple No.3, temperature was increased slowly by infiltration of the molten alloy by the reducing pressure. It was shown that the fast infiltration of the molten alloy occurred at the applied pressure compared with that in other positions. It can be seen from Figs. 3-5 that the molten alloy starts to flow from Nos. 1 and 2 to Nos.3-8. The infiltrations at pressure acceleration times of $1 \mathrm{sec}, 2 \mathrm{sec}$ and $5 \mathrm{sec}$ are complete in $0.4 \mathrm{sec}, 0.8 \mathrm{sec}$ and $1.2 \mathrm{sec}$ respectively. Under these conditions, an FeCrSi preform has been successfully infiltrated by the low-pressure casting process.

\section{2 Porosity of piston head parts}

The piston head parts are porous as a result of solidification and imperfect infiltration. The relationship between this porosity and pressure acceleration times ( $1 \mathrm{sec}, 2 \mathrm{sec}$ and $5 \mathrm{sec}$ ) can be seen in Fig. 6. This figure shows the porosity by solidification of molten alloy around the reinforcement. It can be seen that there are numerous porosities at the beginning of infiltration inside the preform at a reducing pressure $(-0.09 \mathrm{MPa})$. That is the porosity 


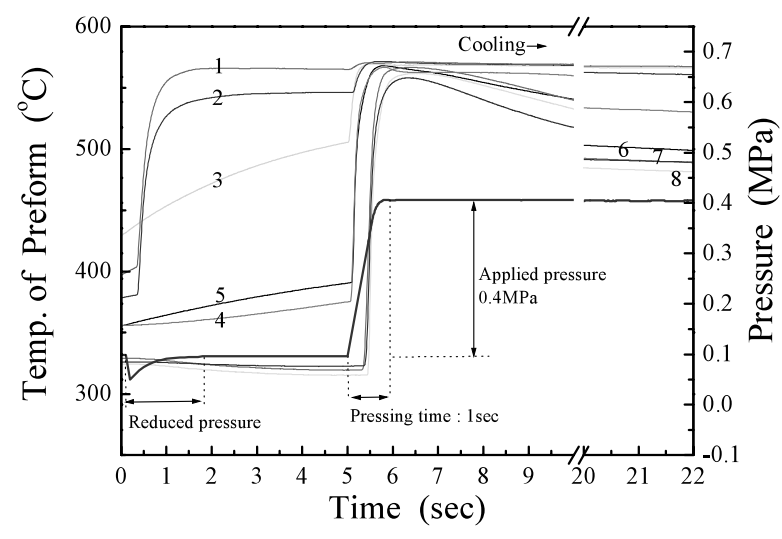

Fig. 3 Infiltration velocity of molten alloy in preform at pressure of $0.4 \mathrm{MPa}$ and pressure acceleration times of $1 \mathrm{sec}$

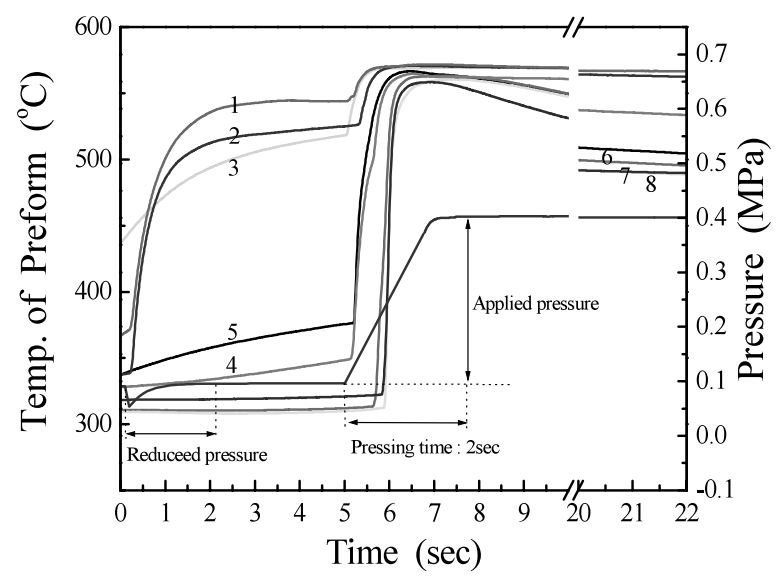

Fig. 4 Infiltration velocity of molten alloy in preform at pressure of $0.4 \mathrm{MPa}$ and pressure acceleration times of $2 \mathrm{sec}$

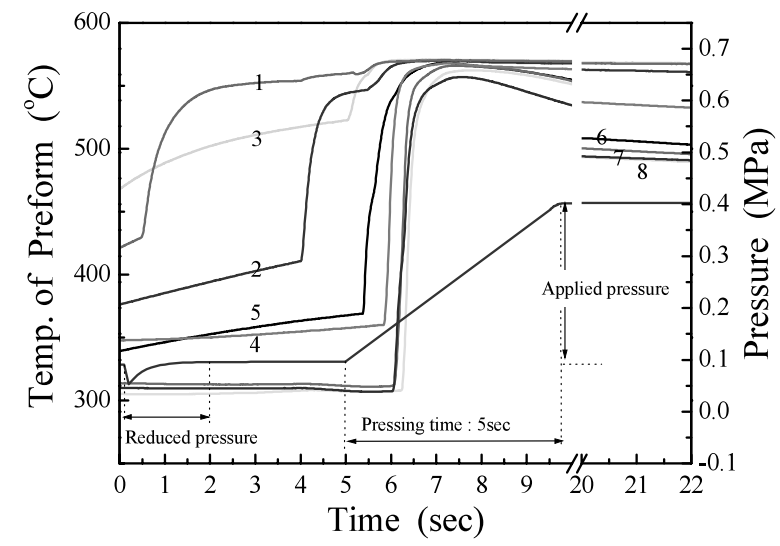

Fig. 5 Infiltration velocity of molten alloy in preform at pressure of $0.4 \mathrm{MPa}$ and pressure acceleration times of $5 \mathrm{sec}$

in this part is expected to increase, which is the beginning of infiltration inside the preform with solidification of molten alloy around the FeCrSi fiber, because of the reducing pressure in the air vent for $5 \mathrm{sec}$ for removing the air in the preform. However, we detected a decrease the

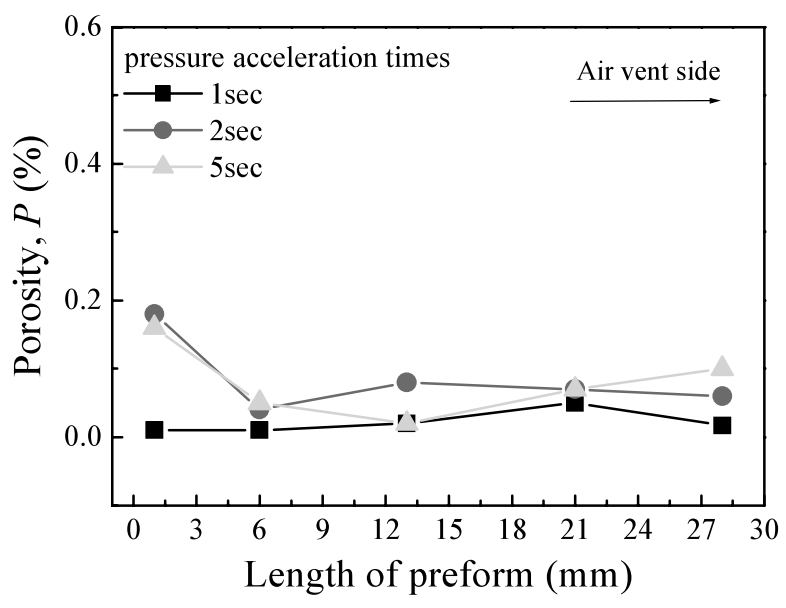

Fig. 6 Influence of solidification with pressure acceleration times of $1 \mathrm{sec}, 2 \mathrm{sec}$ and $5 \mathrm{sec}$ on porosity

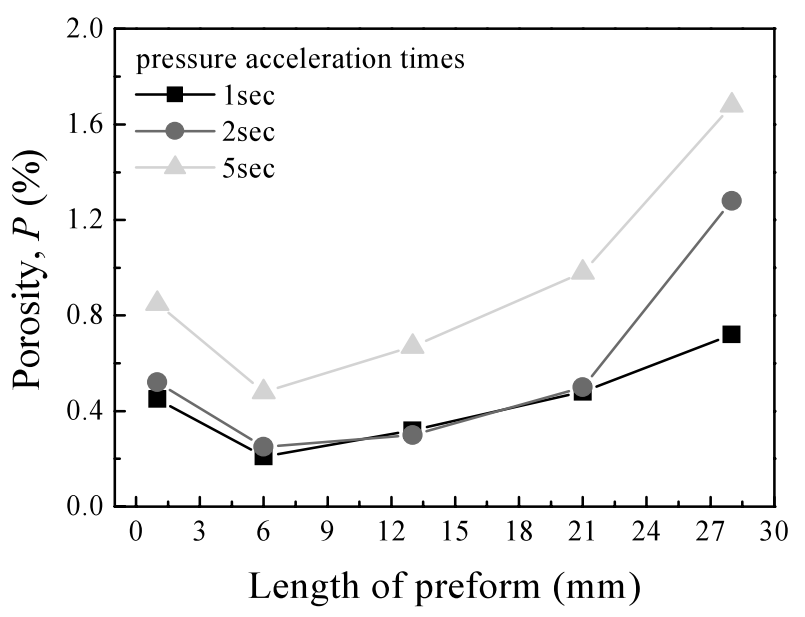

Fig. 7 Influence of imperfect infiltration with pressure acceleration times of $1 \mathrm{sec}, 2 \mathrm{sec}$ and $5 \mathrm{sec}$ on porosity

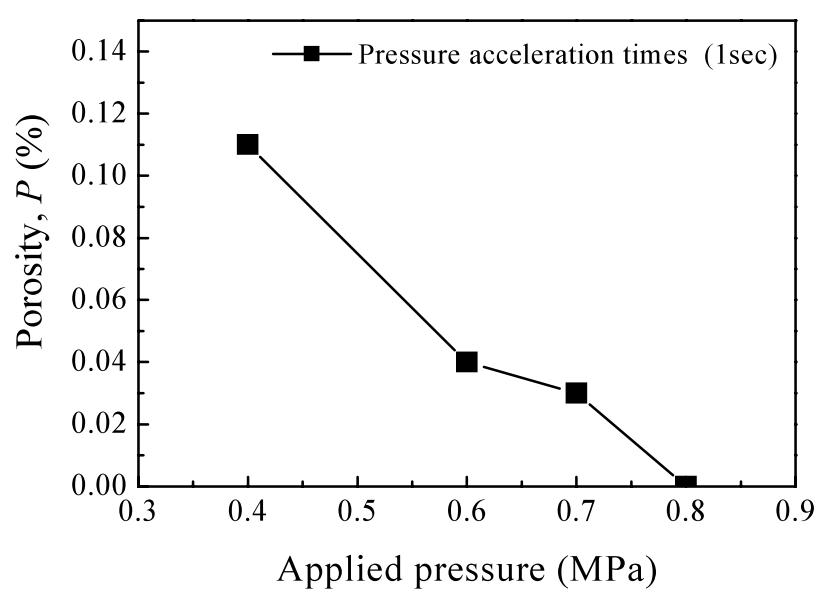

Fig. 8 Effect of applied pressure of $0.4-0.8 \mathrm{MPa}$ on porosity

porosity of the part from $6 \mathrm{~mm}$, which was caused by the applied pressure. Figure 7 shows the porosity caused by imperfect infiltration. From this figure numerous porosities can be seen observed at the side of the mould compared with the beginning of infiltration inside the preform. 

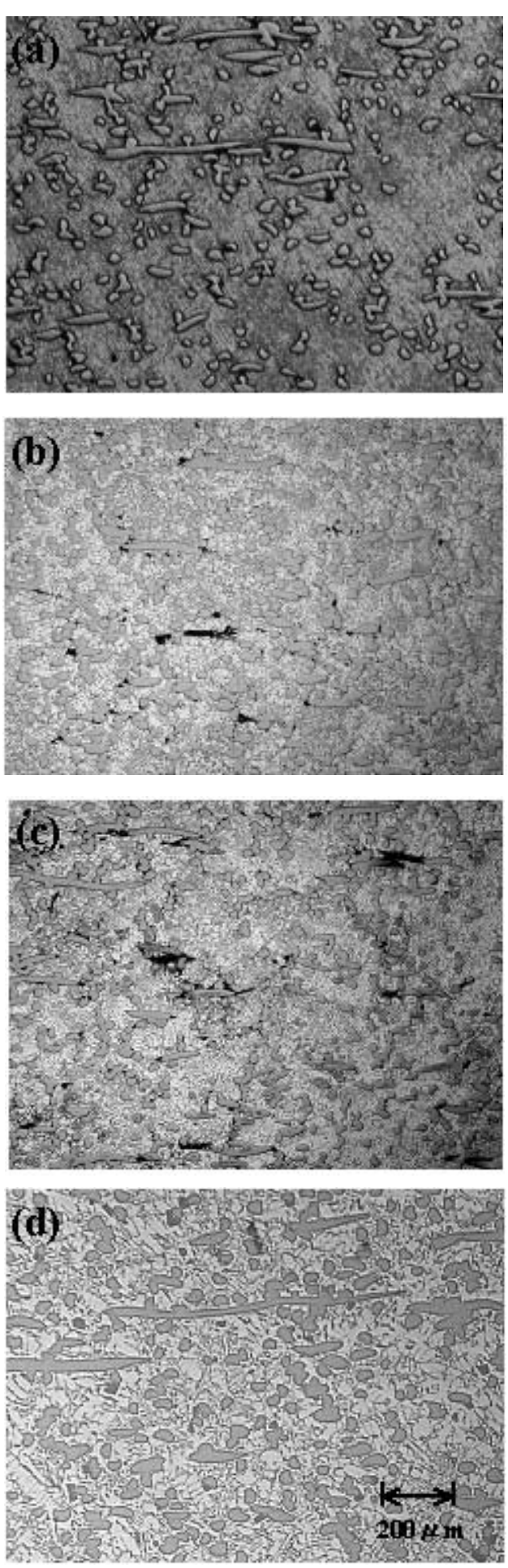

Fig. 9 Optical micrographs showing porositiy; (a) $0.4 \mathrm{MPa}$, (b) $0.6 \mathrm{MPa}$, (c) $0.7 \mathrm{MPa}$ and (d) $0.8 \mathrm{MPa}$ applied pressures

An increase in porosity by the rapid decrease in temperature of the molten alloy was expected because the mould was $200^{\circ} \mathrm{C}$. Moreover, the applied pressure was not sufficient. However, in the case of the pressure acceleration times of $1 \mathrm{sec}$, a small porosity was observed compared with those in the cases of $2 \mathrm{sec}$ and $5 \mathrm{sec}$. Figure 8 shows

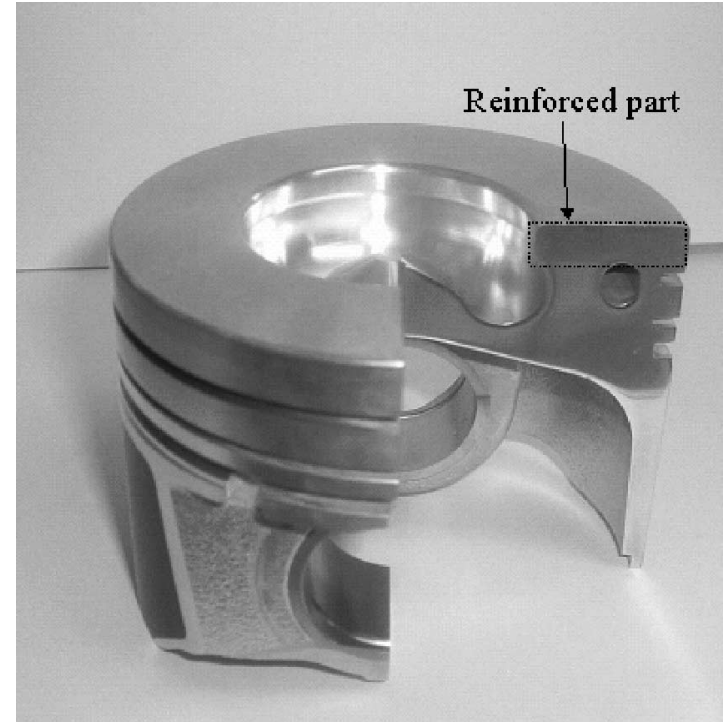

Fig. 10 FeCrSi/A336.0 aluminum alloy composite fabricated by low-pressure casting process with $0.8 \mathrm{MPa}$

the results of porosity in the composite fabricated under applied pressures of $0.4 \mathrm{MPa}$ to $0.8 \mathrm{MPa}$. In the case of an applied pressure of $0.8 \mathrm{MPa}$, there was perfect infiltration in the preform. Porosity is dependent on applied pressure and pressure acceleration times. Furthermore, the low-pressure casting process promotes the infiltration of molten aluminum in to preform and leads to the degradation of pores. Therefore, the low-pressure casting process is very effective for the fabrication of $\mathrm{FeCrSi}$ reinforced piston head parts. As seen in Fig. 9, this study revealed that the porosity of materials varied with different applied pressures. From this photograph it can be seen that there is no porosity at the applied pressure of $0.8 \mathrm{MPa}$. Under these conditions, $\mathrm{FeCrSi}$ fiber preforms have been successfully infiltrated using the low-pressure casting process. Figure 10 shows the engine piston with $\mathrm{FeCrSi}$ reinforced aluminum alloy composite. The dark region in the piston, which is in the upper edge of the piston, is the composite part. The quadrangle part of the piston is the composite. A high fatigue strength and a good wear resistance at high temperature are required for this part. Usually, the mechanical properties and reliability of composites are related to porosity. Accordingly, in this study the developed automobile piston with $\mathrm{FeCrSi}$-reinforced aluminum alloy can have $0 \%$ porosity under the conditions of optimal applied pressure and pressure acceleration times.

\section{Conclusions}

The low-pressure infiltration process is very effective for $\mathrm{FeCrSi}$-reinforced aluminum alloy composite fabrication. The infiltration in the preform at pressure acceleration times of $1 \mathrm{sec}, 2 \mathrm{sec}$ and $5 \mathrm{sec}$ is completed in $0.4 \mathrm{sec}$, $0.8 \mathrm{sec}$ and $1.2 \mathrm{sec}$. Under these conditions, the $\mathrm{FeCrSi}$ fiber preform was successfully infiltrated by low-pressure 
casting. Furthermore, to check the reliability of the composite, the porosity of the composite was observed and an automobile piston with $\mathrm{FeCrSi}$-reinforced aluminum alloy was developed. A composite with $0 \%$ porosity could be fabricated under the conditions of optimal applied pressure and pressure acceleration times.

\section{Acknowledgements}

The authors would like to express their gratitude to the Hiroshima Prefectural Institute of Industrial Science and Technology for their financial support and their technical assistance in this study.

\section{References}

( 1 ) Donomoto, T., Miura, N., Funatani, K. and Miyake, N., Ceramic Fiber Reinforced Piston for High Performance Diesel Engines, SAE Tech. Paper No.830252, (1983).

( 2 ) Bedwell, T., MMC Pistons a Solution for 1990's High
Output Diesels, SAE Tech. Paper No.890595, (1989).

( 3 ) Westengen, H. and Holta, O., Low Pressure Permanent Mould Casting of Magnesium-Recent Developments, Foundry Trade Journal, Vol.163 (1989), pp.738-742.

( 4 ) Morimoto, S., Ohnishi, N. and Okada, S., Development of a Low-Pressure Die Casting Process for Improved Soundness of Aluminum Castings, AFS Transactions, Vol.20 (1987), pp.39-46.

( 5 ) Onishi, N., Aizawa, T. and Okada, S., Development of Inert Gas Low-Pressure Die Casting Process, JACT News, 355 (1986), pp.283-298.

( 6 ) Oda, N., Fujita, M., Sugimoto, Y., Teshima, K., Arita, K. and Kuramoto, T., Development of Diesel Engine Composite by Low-Pressure Casting, Mazuda Tech. Rev., Vol.49 (1999), pp.37-43.

(7) Sasaki, G., Processing of Aluminum Alloy Matrix Composites and Its Application for Automobile Parts, Proc. 8th Japan International SAMPE Symposium, Vol.2 (2003), pp.805-808. 